\title{
LOS BASATINN SAADIANOS DE FEZ ASPECTOS DE LA ARQUITECTURA DEFENSIVA EN MARRUECOS A FINALES DEL SIGLO XVI
}

Por: Montaser LAOUKILI, Arqueólogo-Historiador del Arte

\section{INTRODUCCIÓN}

Desde su fundación, y durante la Edad Media, la ciudad de Fez tuvo siempre una gran importancia en la historia política, social y militar del Occidente musulmán. Aunque los saadianos eligieron Marrakech como capital del sultanato, Fez guardaba su título de ciudad estratégica donde se había hecho el juramento de fidelidad "bai' a" de Ahmed al-Mansur ad-Dahbi tras la batalla de Alcazarquebir en el año 986 H/ 1578 J.C.; y según las fuentes, Fez era el centro neurálgico de las relaciones del Sultanato con el imperio otomano de Estambul ${ }^{1}$.

La entrada de los saadianos en Fez tuvo lugar en el 956 H/ 1549 J.C con muchas dificultades; además de la resistencia de los Uatasides al ejército saadiano, las viejas murallas de época almohade y meriní estaban bien fortificadas (Fig. 1).

La descripción de Fez por Mármol, que la visitó durante el reino de Abdelah al-Ğālib, nos hace saber que la fortificación estaba limitada a una doble muralla con torres, que no permitía asegurar una defensa de la ciudad por la inexistencia de bastiones adaptados a las armas de fuego ${ }^{2}$.

Gracias al texto de un historiador anónimo, podemos saber que la Qasaba de Tamdert fue fundada por Muhamed ash-Shaih que empezó su construcción en el $956 \mathrm{H} /$

1. Al-Ifrani, Mohamed as-Saguir "Nuzhat al-hadi fi Ajbar muluk al-qarn al-hadi" (la vida de los reyes del siglo once), Rabat, 1998, p. 150.

2. Mármol de Carvajal, “África”, traducción al árabe por Mohamed Hağği y otros, segundo tomo, edición nashr al-ma'rifa, Rabat, 1988-1989, p. 158. 


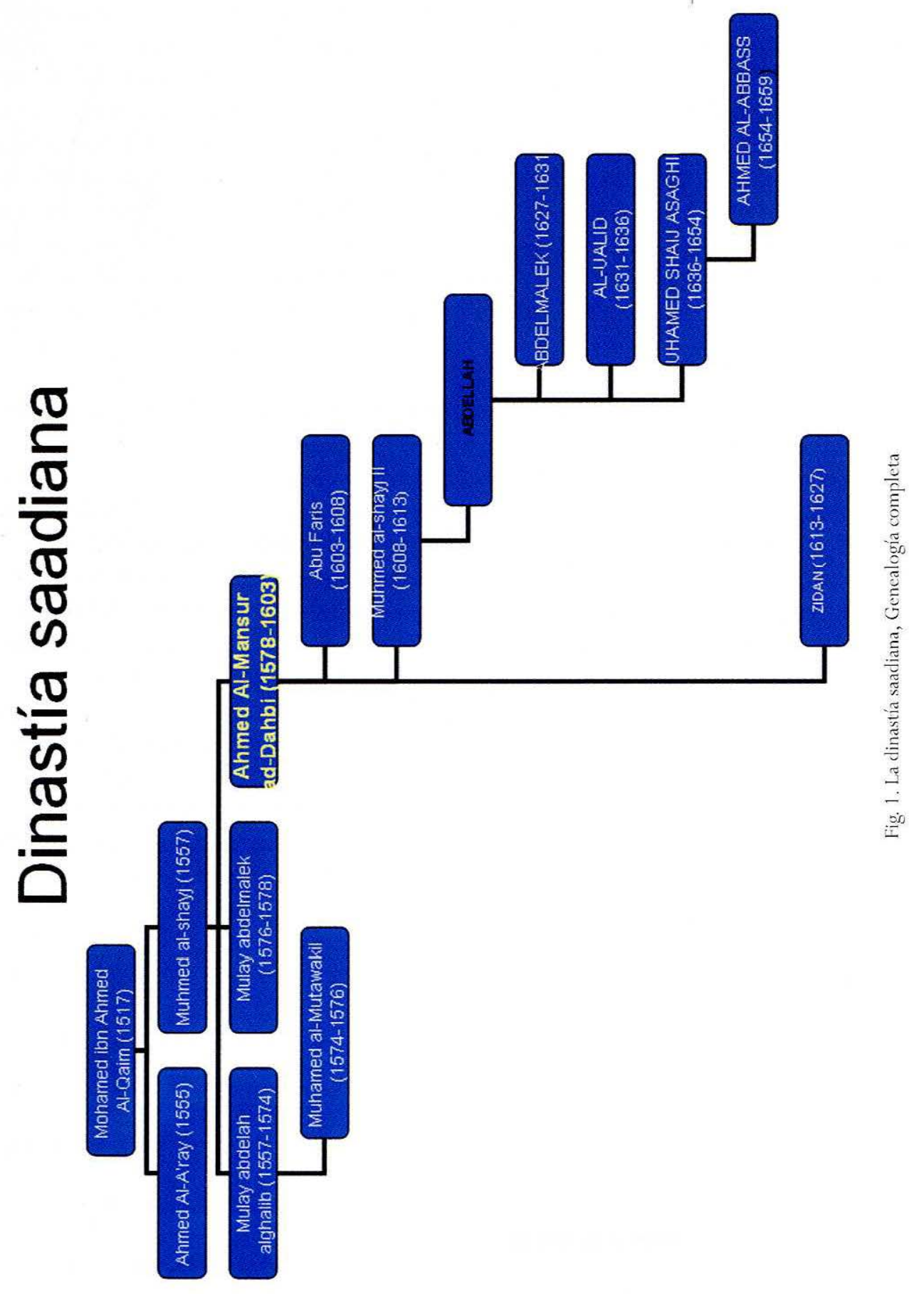


1549 J.C ${ }^{3}$. Sin embargo, el sistema defensivo de Fez presentaba una arquitectura arcaica, y sin gran eficacia para resistir a los peligros de la época. Por esas razones, los finales del siglo XVI conocían una arquitectura defensiva desarrollada. El contraste fuerte entre arquitectura defensiva medieval y elementos adjuntos modernos, que sirven más a la adaptación de la artillería y las armas de fuego en el cuerpo arquitectural del bastión nos empuja a pensar en esta conciencia del cambio histórico causado por la introducción de las nuevas armas en la guerra; teniendo en cuenta las nuevas circunstancias, y a través de la influencia europea, aparecía en Marruecos en el siglo XVI el concepto de la arquitectura abaluartada de los bastiones: de la arabización de este vocablo militar latino aparece el término: "bastiun" singular y "basatîn" en plural que utilizaron varias fuentes (al-Fashtali, al-Ifrani, ... $)^{4}$.

Combinando la documentación textual y la observación de la arqueología monumental podemos aclarar las características de las fortificaciones saadianas de Fez.

El número y la cronología de los bastiones que flanqueaban la muralla de Fās al-Ğdīd no están aclarados por las fuentes históricas. Al-Fashtali escribía que Ahmed al-Mansur rodeaba Fez por "Al-Abrağ Ad-dajma” (bastiones grandes) adosadas a la muralla ${ }^{5}$, mientras que Al-Ifrani cuenta el incidente diplomático entre Ahmed al-Mansur y el emperador Murad otomano que empujó al califa turco a llevar un ejército a Marruecos y empujó a Ahmed al-Mansur a fortificar la ciudad de Fez y otros lugares ${ }^{6}$.

Las circunstancias históricas del siglo XVI en Marruecos y su entorno necesitaban una protección de la parte Norte de Marruecos, más cerca del peligro extranjero (español, otomano, ...), una línea defensiva de bastiones se dibuja entre Taza, Fez, y Larache permitiendo al poder saadiano proteger su frontera norte de los ataques exteriores.

El presente trabajo estará focalizado sobre la arquitectura y la historia de los Burğ (o Bordj) Norte y Sur por las características específicas que presentan, se aludirá también a dos "basatîn" de la misma época en la muralla de Fās al-Ğdīd.

3. Mayhul (anónimo), "Tarij ad-daula as-saadia at-tagmdartia" (Historia del Estado Saadino Tagmedarti), edición oiun makalat, Marrakech, 1994, p. 29.

4. La toponimia "bastión" se utiliza hoy por los habitantes de la ciudad de Taza (Norte oriental de Marruecos) para designar el famoso fuerte.

5. Al-Fashtali, Manahil as-safa fi Ajbar al-muluk ash-shurafa" (la vida de los reyes cherifianos),

6. Al-Ifrani, op. cit, p. 156. 


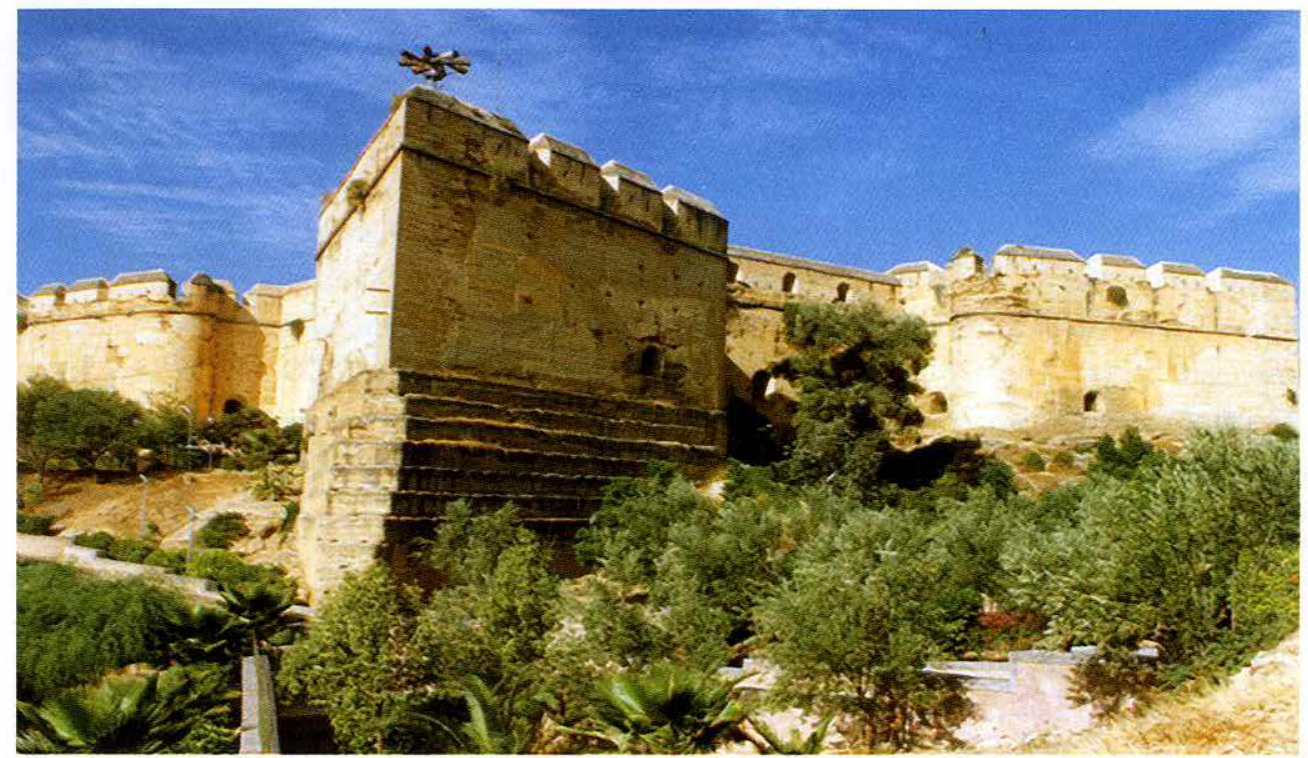

Fig. 2. Vista del bordj antes de su restauración.

\section{EL BURĞ NORTE}

\section{Historia:}

El Burğ (bordj o bastion) está situado sobre un espolón que domina la medina de Fez «Fez el Bali» por el lado norte, por la parte oeste de las ruinas de la Necrópolis de los merinidas, y que ocupa según las fuentes históricas el emplazamiento de un musilla de la época de Beni Merin

El fuerte fue edificado bajo el reino del sultán saadi Ahmed El Mansur Eddahbi en 1582 frente al Bastión Sur (edificio construido en la misma época). Los dos fuertes recibían el apoyo de los cautivos portugueses. La concepción de los fuertes de Fās al-Ğdīd, respondió al objetivo de proteger la ciudad de Fez tanto de los posibles ataques del interior (las cabilas rebeldes) como del exterior (los otomanos de Argelia). Esos edificios son testigos de una nueva concepción en la realización de fortificaciones militares que empiezan a recibir las piezas de artillería (Fig. 2).

7. Al-Mannuni, Muhammed,"dirasat mujtara" (estudios selectivos), edición del Ministerio de Cultura, Rabat, 2002, p. 143. 


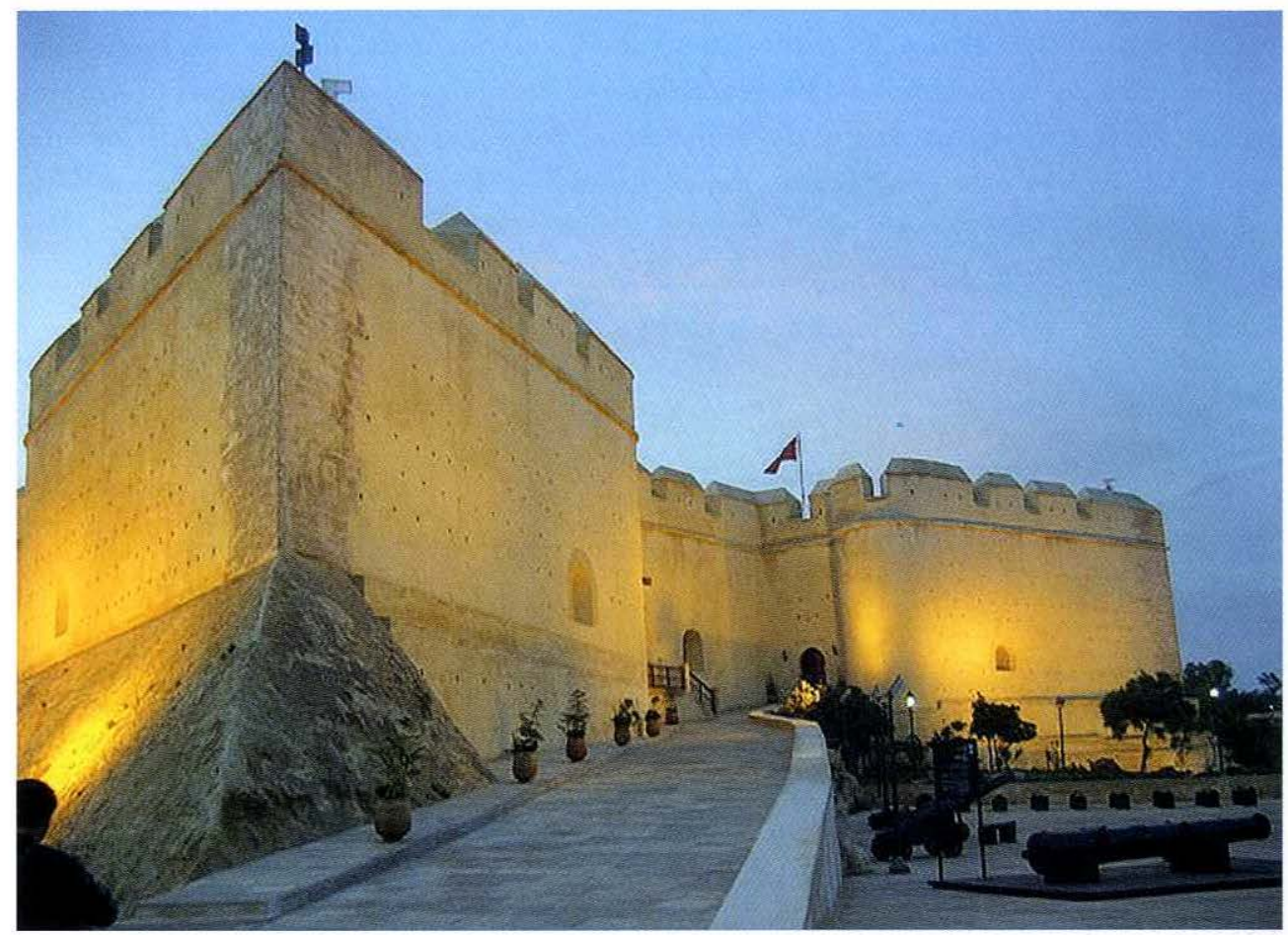

Fig. 3. El bordj después de su restauración.

Bajo el protectorado, este monumento fue ocupado por los miembros de la resistencia nacional a la ocupación francesa, antes de que los franceses lo ocuparan y lo utilizaran como cuartel y cárcel.

Después de su restauración por el servicio de Bellas Artes entre 1962 y 1963, el edifico ha sido rehabilitado como Museo de Armas que provienen del arsenal de Mulay Al-Hasan primero «Makina» ${ }^{8}$ (Fig. 3).

\section{Descripción:}

El Burğ Norte se caracteriza por la armonía morfológica de su plan, y el equilibrio de sus proporciones. Con una superficie de $2265 \mathrm{~m}$ en el plano y entre

8. Mokaddem, Hafid., "La réhabilitation du musée des armes (Borj Nord) à Fès", in: Patrimoine Marocain, Revue de l'ALINSAP, n¹ - Mars 2008, Tánger, p. 18. 
$11 \mathrm{~m} 40$ y $12 \mathrm{~m} 80$ de altura. Se compone de un núcleo cuadrado, flanqueado en las cuatro esquinas de volúmenes arquitecturales cuyas fachadas forman ángulos punzantes presentando la forma de flecha. La concepción del plano debería existir a finales del siglo XVI, fecha de su edificación como apoya la cita del Fachtali, historiador de la época saadiana (Fig. 4).

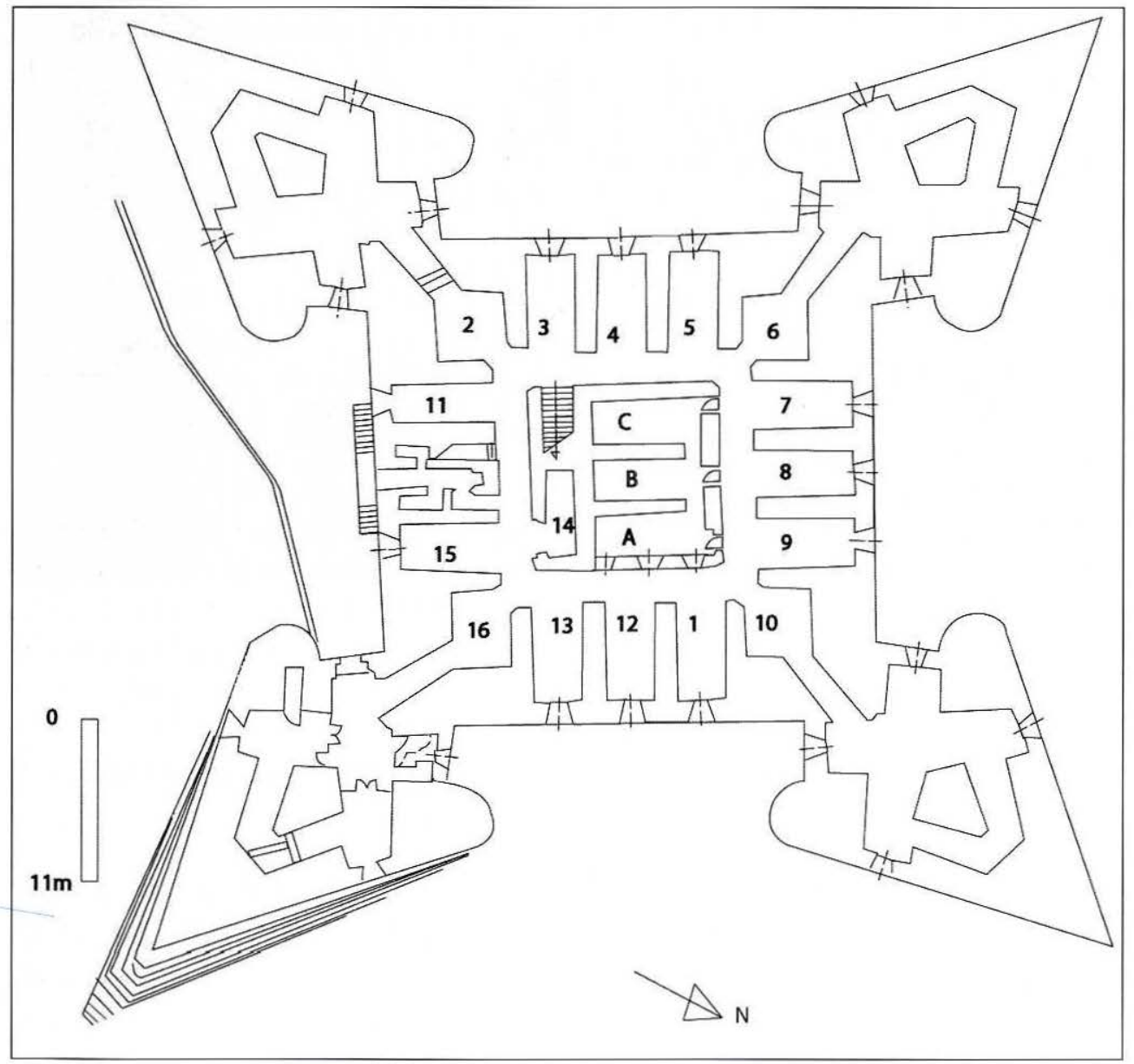

Fig. 4. El Bordj Norte, Plano de los espacios interiores

La entrada del edificio está situada en el centro de su fachada sur (Fig. 5), se trata de una puerta con un arco sobrealzado que lleva a un pequeño vestíbulo a doble codo flanqueado por dos pequeñas celdas laterales, el vestíbulo comunica con un corredor o circuito cerrado, llevando al mismo punto de partida entorno a un núcleo ar- 


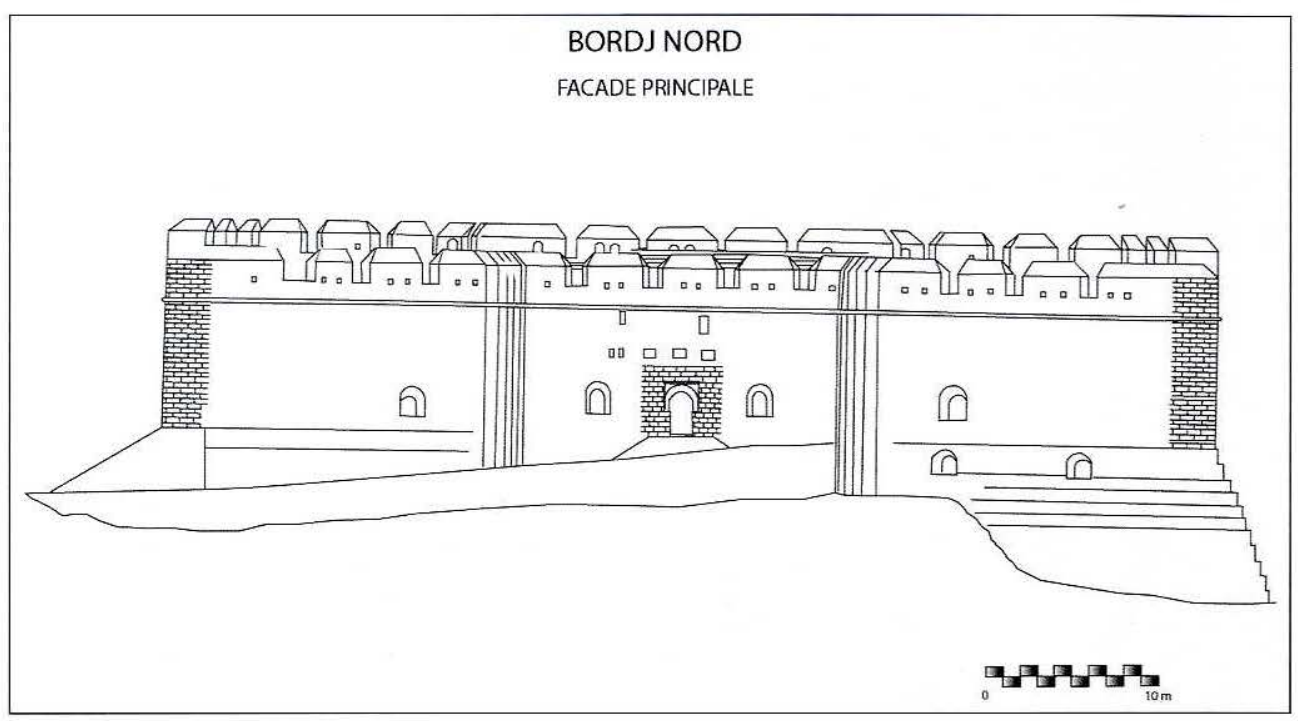

Fig. 5. El Bordj Norte, Plano de los espacios interiores

quitectónico central. El corredor pone en comunicación 15 celdas, 4 alas, y la escalera del piso. Podemos distinguir 11 habitaciones laterales, más profundas que anchas para contener las piezas de artillería, tres salas en la parte norte del núcleo central deberían ser destinadas al depósito de la manutención, en cuanto a la última sala, más estrecha que las precedentes, comporta en el suelo una entrada al aljibe situado abajo.

Cada sala se compone de una antecámara cuadrada, un pequeño vestíbulo, y un corredor que sigue la línea del núcleo central.

Las salas, como las alas, están perforadas por huecos en forma de troneras. El ala sur este presenta una particularidad teniendo dos cámaras en el subsuelo que tienen dos huecos en la parte sur del Burğ. Se puede entrar a la primera celda por una abertura situada en el espesor del muro de la esquina oeste del ala (Fig. 6).

La planta baja tiene dos escaleras, la primera con función secundaria, situada al lado izquierdo de la entrada, comunica el entresuelo con una gran sala (actual despacho del Conservador) y las terrazas. La segunda, principal, más larga lleva al piso superior comunicando con las terrazas, era al origen una rampa central.

El piso: se compone de un patio central rectangular abierto al cielo, bordeado en los lados norte, este, y oeste, por una casamata, y al lado sur de la bóveda que 


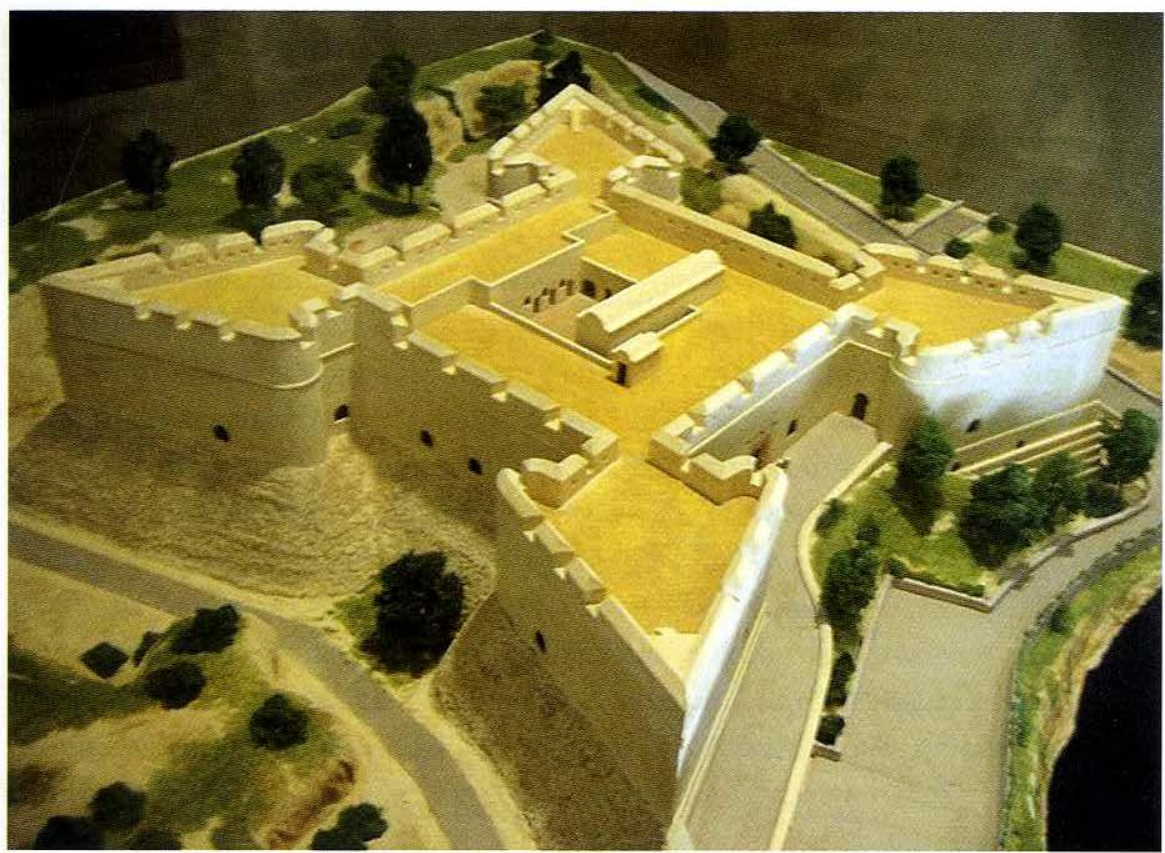

Fig. 6. Bordj Norte. Maqueta.

cubre la caja de las escaleras de las terrazas, por un corredor que lleva a ambas habitaciones, que deberían ser destinadas al alojamiento de los soldados.

Las terrazas están limitadas por acróteras de $2 \mathrm{~m} 15$ perforadas con aberturas que facilitan la colocación de cañones y de diferentes armas de fuego sobre la muralla. Los niveles del suelo son distintos y sus enlaces están asegurados por dos cajas de escaleras. El primer nivel, situado al norte de la entrada del piso, presenta una elevación de $1 \mathrm{~m} 60$ respecto a los otros espacios.

Para sentarse los soldados se servían de las banquetas que permitían también el control desde lejos de todo movimiento del enemigo fuera del fortín.

La terraza comprende 28 mangas de ventilación, cada una presenta una forma cuadrada con $0.50 \mathrm{~m}$ en la altura de cada lado para asegurar la luz y la aireación del corredor de la planta baja.

Las dos escaleras que llevaban a la terraza no tenían en su origen ningún techo, y están cubiertas de bóvedas de hormigón. 


\section{Materiales y técnica de construcción:}

El edifico está hecho en su mayor parte en tapial «tabiya» con unas cantidades de cal que se emplean con una fuerte concentración en los muros a espesores variables hasta de $3 \mathrm{~m} 30$. Las aberturas y los huecos son aparejados de ladrillos puestos alternativamente con unas capas de mortero de arena y cal. El ladrillo se utiliza también en las coberturas construidas en las bóvedas.

En la parte de las esquinas redondeadas de los salientes, los remates son aparejados en piedras entalladas de color gris que provienen probablemente de un lugar cercano al cerro (Fig. 7).

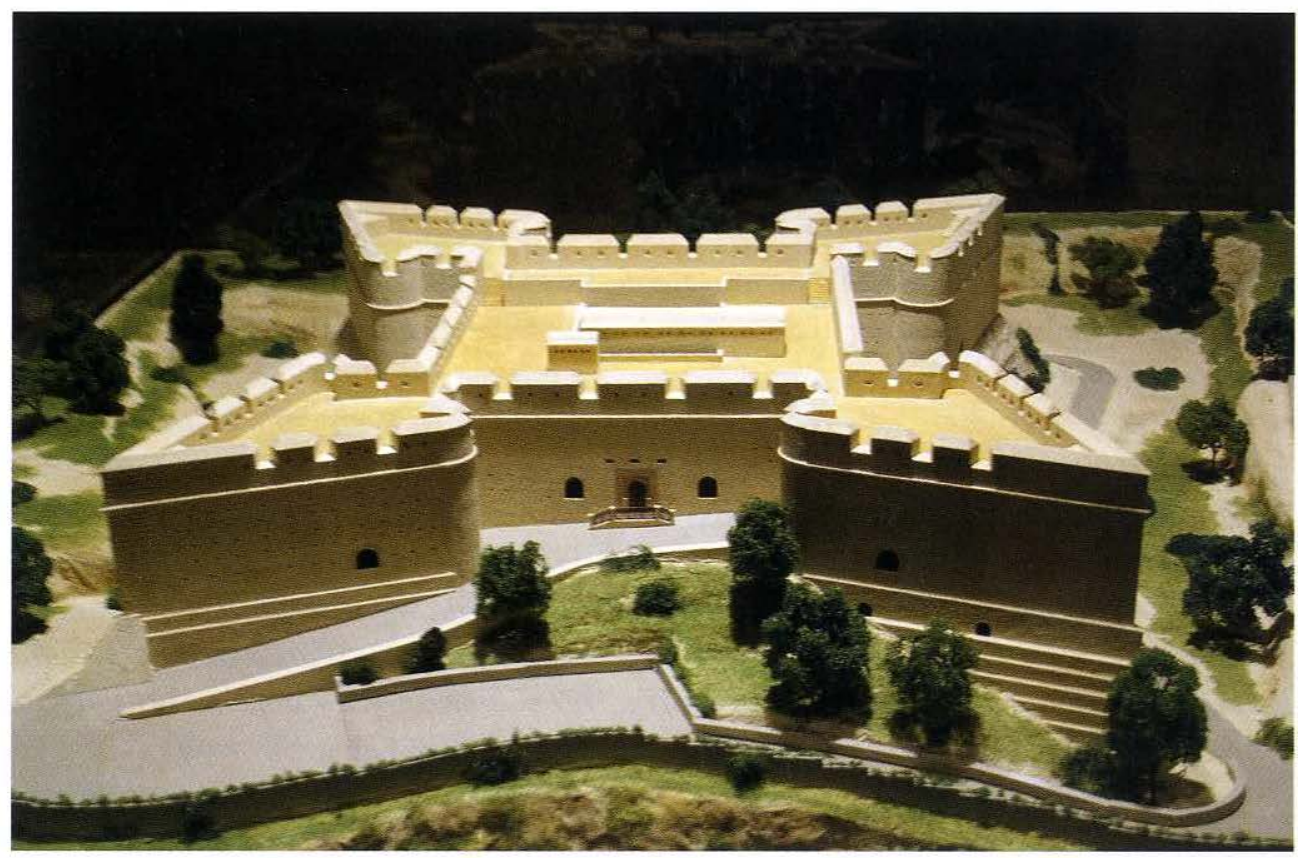

Fig. 7. Bordj Norte. Maqueta.

La juntura entre el tapial y la piedra tiene una forma irregular, la piedra se emplea en los montantes de los arcos de la entrada del edifico y del vestíbulo.

Los fragmentos de piedras están mezclados con la arcilla y la cal para ser empleadas en el talud que bordea el fuerte por los cuatro lados. 


\section{Materiales y técnica de decoración:}

Los elementos de decoración son las formas de los techos en bóvedas, el arco sobrepasado de la entrada y el vestíbulo, y los arcos a cintras llenas de las puertas, de los huecos interiores y exteriores. El arco de la entrada se caracteriza por sus claves de piedras entalladas y sus mochetas amenizadas de dos veneras talladas en hueco.

Las esquinas de los muros interiores se rematan en molduras en media caña, en armonía con las curvas de los arcos y de las bóvedas?.

\section{EL BURĞ SUR}

Edificado en año 1582 por las mismas razones y con el mismo destino que el Bastión Norte, el fuerte Sur fue construido sobre «Hağar El Katran», una alta colina rocosa que domina la medina de Fez por la parte Sur, fuera de las murallas. Las fuentes históricas lo designan con la denominación de «fuerte de Bab Ftouh». An-Nasiri hacía alusión a su empleo por el sultán alauita My Abderrahman (1822-1859) para lanzar golpes de cañones y proyectiles contra los Udayas que bombardearon el fuerte de la parte Sur.

Los trabajos de restauración han recuperado algunas marcas (huellas) de dos bolas en la parte sur de la fachada punzante del fuerte, pero no se puede saber si son huellas de esa época o de la época del protectorado, como lo estipulan los habitantes del barrio vecino al fuerte.

\section{Descripción}

De forma alargada, el edificio presenta una parte en ángulo agudo que se puede ver a partir de dos salientes rectangulares simétricos, otro saliente, de la misma disposición, ocupa el centro de la fachada Norte-Oeste (Fig. 8).

Una puerta de acceso rectangular a dos batientes de madera ha sido perforada - posiblemente en la época del protectorado- en el flanco Sur de la parte en ángulo. Una poterna se encuentra en el lado Oeste comunicando con una cámara interior actualmente cerca de la celda del vigía (Fig. 9).

9. Ibíd., p. 19. 


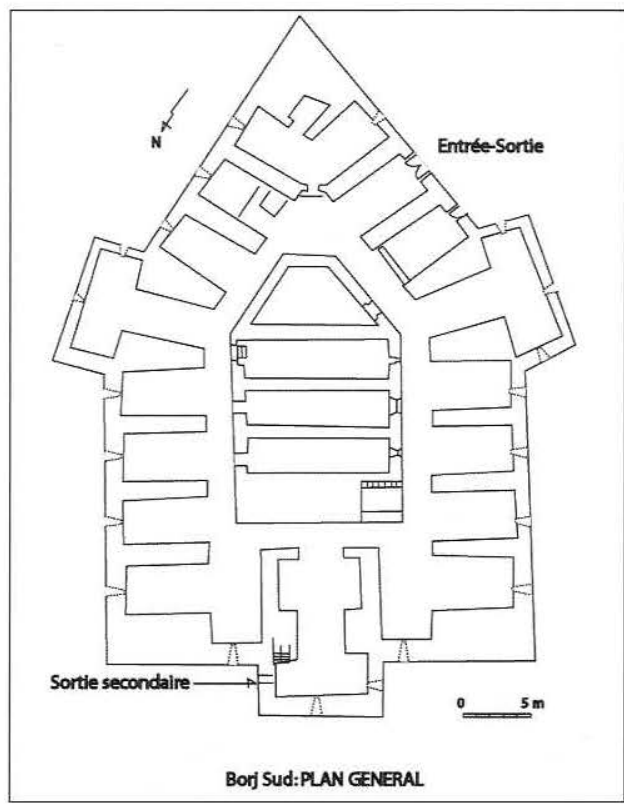

Fig. 8. Burğ Sur, Plano de los espacios interiores

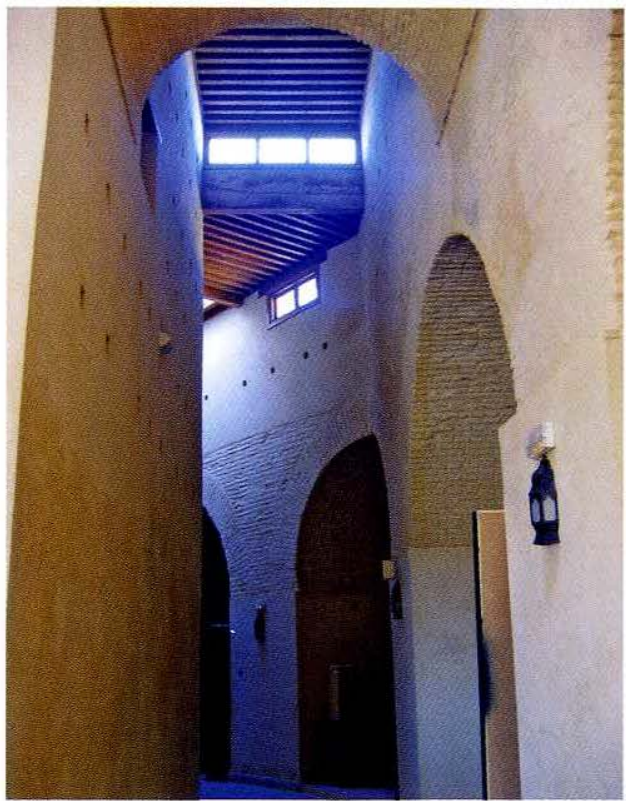

Fig. 9. Burğ Sur, interior.

La puerta inicial del fuerte se encontraba - como lo han demostrado los trabajos en la obra de restauración- en el lado del saliente Norte Oeste.

La elevación de esta puerta en relación con el nivel del suelo le permite dominar la vista de toda la ciudad y sus arrabales inmediatos. Una larga escalera comunicaba antes con la parte baja del cerro rocoso donde está el edificio. La meseta que permite la comunicación con la antigua bahía ha sido completamente destruida. El hueco ha sido empleado en tronera aparejada de ladrillos.

Los restos de su encuadramiento de ladrillos aparecen sobre el muro. Otros huecos del mismo tipo, condenados actualmente, debían estar dispuestos en una línea regular sobre las partes exteriores del fuerte, destinados a recibir las piezas de artillería y asegurar la iluminación de las cámaras en el interior. Esos cuartos con disposiciones diferentes están en la planta baja; la mayoría son de forma rectangular, al nivel de los salientes Este y Oeste y están dispuestas una salas en forma de T (Fig. 10).

El saliente Norte-Oeste en T, constituyendo en su origen el vestíbulo de la entrada y comprende - al lado de la entrada del fuerte- una caja de escalera en dos partes que lleva directamente a las terrazas. El suelo de la sala "mediana" del flanco Sur 


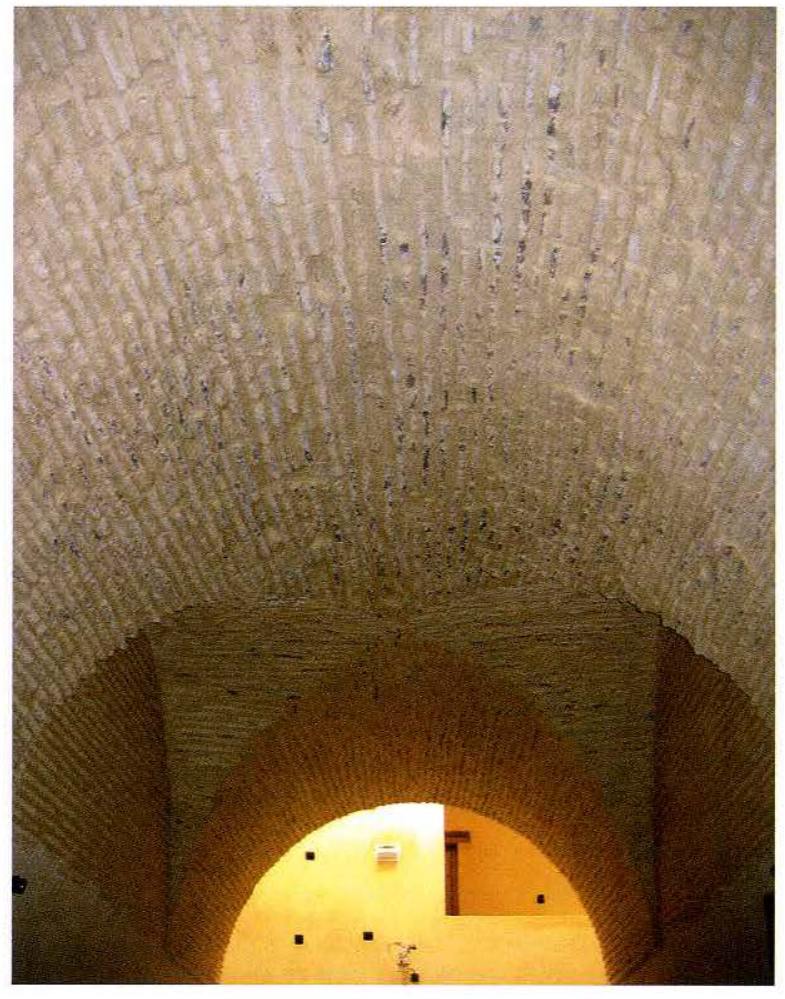

Fig. 10. Burğ Sur, bóveda.

de la fachada en ángulo del edifico contiene una abertura de un aljibe muy profundo. Todas las salas laterales comunicaban con un largo corredor abierto al cielo, rodeando el núcleo central que comprende en la planta tres células profundas que comunican entre ellas por dos pequeños huecos, y otra de forma trapezoidal, que eran probablemente almacenes.

Hacia la parte NorteOeste del núcleo central una rampa recta bordeada de una parte de escaleras comunica con las terrazas y el piso. Las dependencias del piso están encima de las dependencias de la planta del núcleo central.

Las dependencias comprenden un corredor que comunica con dos filas de tres celdillas enfrente, y una celda trapezoidal encima de otra cámara similar situada en la planta. La iluminación y la aireación de este nivel están aseguradas por otros tres huecos cuadrados $(1 \mathrm{~m} 70 \times 1 \mathrm{~m} 70)$ perforados en la misma línea en el techo.

Las terrazas están en dos niveles distintos. El primero remata el núcleo central y las cámaras formando una punzante Sur-Este del fuerte. Sobrellevado por $1 \mathrm{~m} 40$ al segundo nivel que está encima de las células de la planta.

Dos pequeñas partes de escaleras aseguran la comunicación entre los dos niveles, la caja de escalera que lleva desde la entrada a las terrazas al Este sobre el límite de abertura del corredor Norte Oeste de la planta baja. Las terrazas del fuerte están delimitadas por acróteras perforadas en una sucesión de huecos de dimensiones variables, los más largos estaban destinados a recibir las piezas de artillería (cañones) y los huecos estrechos para la orientación las armas de fuego menos grande desde la muralla. 


\section{Materiales y técnica de construcción:}

El edifico está hecho en la mayor parte en tapial "tabiya" con algunas cantidades de cal. Las aberturas y los huecos son aparejados de ladrillos puestos alternativamente con unas capas de mortero de arena y cal.

La juntura entre el tapial y la piedra tiene una forma irregular, la piedra se emplea en los montantes de los arcos de la entrada del edifico y del vestíbulo.

Los fragmentos de piedras están mezclados con la arcilla y la cal para ser empleadas en el talud que bordea el fuerte por los cuatro lados (Figs. 11, 12 y 13).

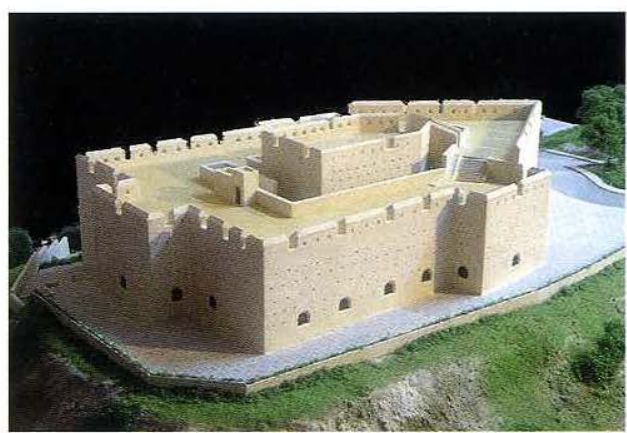

Fig. 11. Bordj Sur, maqueta.

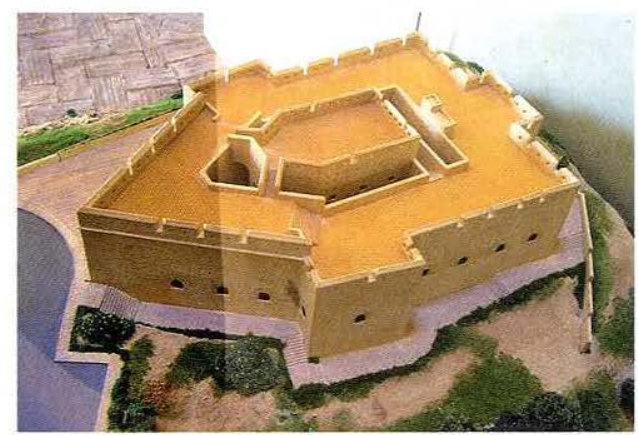

Fig. 12. Bordj Sur, maqueta.

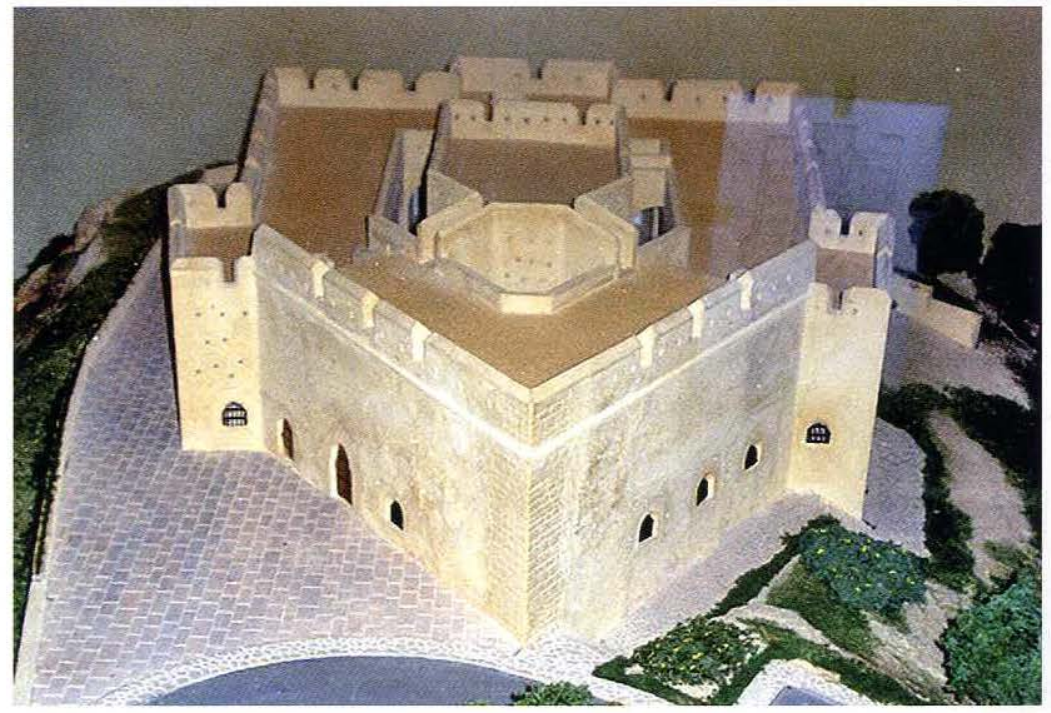

Fig. 13. Bordj Sur, maqueta. 


\section{LAS FORTIFICACIONES SAADIANAS DE FĀS AL-ĞDĪD:}

Entre los bastiones norte y sur de Fez; una línea defensiva adosada a la muralla de Fās al-Ğdīd permite la vigilancia, el control y la defensa del espacio urbano; según Ibn al-Qādi al-Meknasi, Fez tenía bajo el poder de los saadinos nueve fuertes. Sin embargo, la investigación permite destacar diez fuertes, tres adosados al muro oeste de Fās al-Ğdīd, otros tres fuertes están establecidos en el muralla Este (Burğ: Butuil, ašŠayh Ahmad, Sidi Bounafe'), un Burğ al- Ğdīd) al norte des Bab Sba' y que no existe hoy día $^{10}$, y otro al sur de Bab Lamer (Burğ al-Mahraz) demolido por el sultán alauita Mulay Abdellah en el siglo XVIII según R. Le Tourneau ${ }^{11}$, y los dos Bastiones Norte y Sur.

Actualmente, y a través la observación del terreno, conocemos la existencia de los Burğ Sidi Bunafa' (Figs. 14 y 15), aš-Šayh Ahmad, Burğ Butuil, y otros dos bastiones que están actualmente en el interior de la muralla actual del palacio real de Fez ${ }^{12}$. La parte superior de un Burğ se nota desde la avenida llevando a Bab Lamer (Figs. 16 y 17).

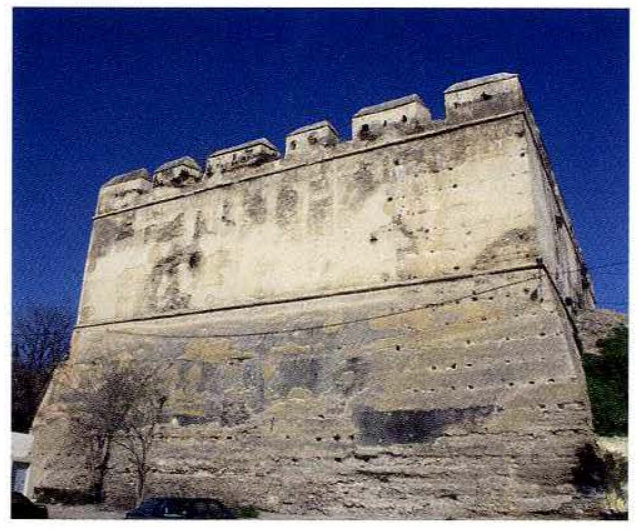

Fig. 14. Burğ Sidi Bunafa.

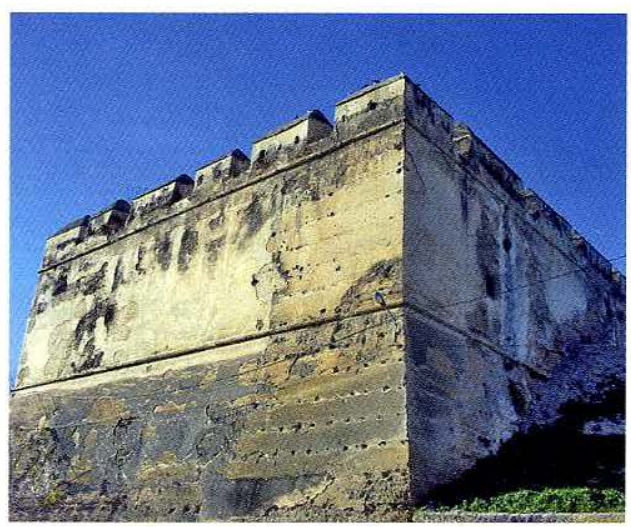

Fig. 15. Burğ Sidi Bunafa.

10. Al-Idrissi, Mohamed Mohcine, "L'espace urbain et l'Architecture de Fas al-Bali à l'époque 'Alawite (jusqu'au Protectorat), 2001-2002, Thèse du troisième cycle de l'Institut Nacional des Sciences de l'Archéologie et du Patrimoine (I.N.S.A.P), p. 105.

11. Le Tourneau, Roger., Fès avant le Protectorat, traducción al árabe por Mohamed Hağği y Mohamed Lakhdar, tomo primero, edición dar al-ğharb al-islami, Beirut, 1992, p. 130.

12. M. al-Mannuni, waraqat an hadarat bani Marin (hojas de la civilización merini), Edición de la Facultad de Letras y de Ciencias humanas, Universidad Mohamed V, Rabat, 1996, p. 47. 


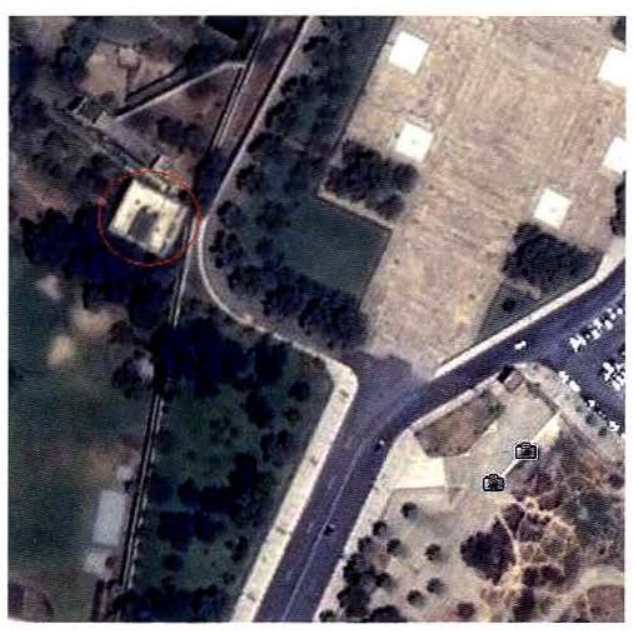

Fig. 16. Imagen de la posición de uno de los bastiones del palacio real, Google Earth

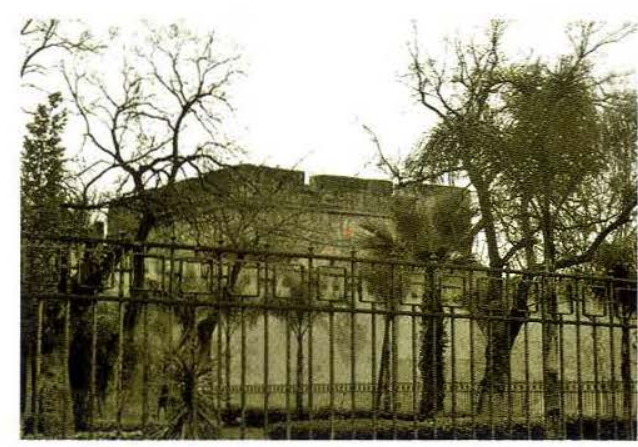

Fig. 17. Fotografía de una fachada del bastión enclavado dentro del palacio real

\section{BURĞ BŪ $\square$ UİL}

Este Burğ está situado entre el Burğ as-Sayh Ahmad y el Burğ Sidi Bunafa. Limitado al Norte, Este, y Sur por el río "oued Fez" y la avenida de "la Libertad"; al oeste se encuentra el barrio y la calle llamados Butuil donde está situada la única entrada al edifico por este lado.

Apoyado sobre una plataforma, el edifico tiene una morfología casi cuadrada (23.90 m. x 21.85m) más grande que el Burğ Shayj Ahmad. El acceso a la planta baja se hace desde el lado Oeste, donde las nuevas deformaciones del espacio han causado un cambio en la fachada Oeste (Figs. 18 y 19).

En el interior del edificio, un espacio rectangular de dirección Norte-Sur con dos aberturas para cañones sobre las partes laterales Norte y Sur. A través de un paseo de dirección Este-Oeste, se nota la presencia de seis casamatas en los lados Sur y Sur Este y tres sobre los lados Norte y Norte-Sur. Una última casamata está situada en el centro de la fachada Este.

Las esquinas norte-este y sur-este constituyen unas masas arquitecturales importantes similares a los fuertes aš-Šay $\underline{h}$ Ahmed y Sidi Bunafa'. Está cubierto por una serie de bóvedas que soportan las cargas de la terraza (Fig. 20). 


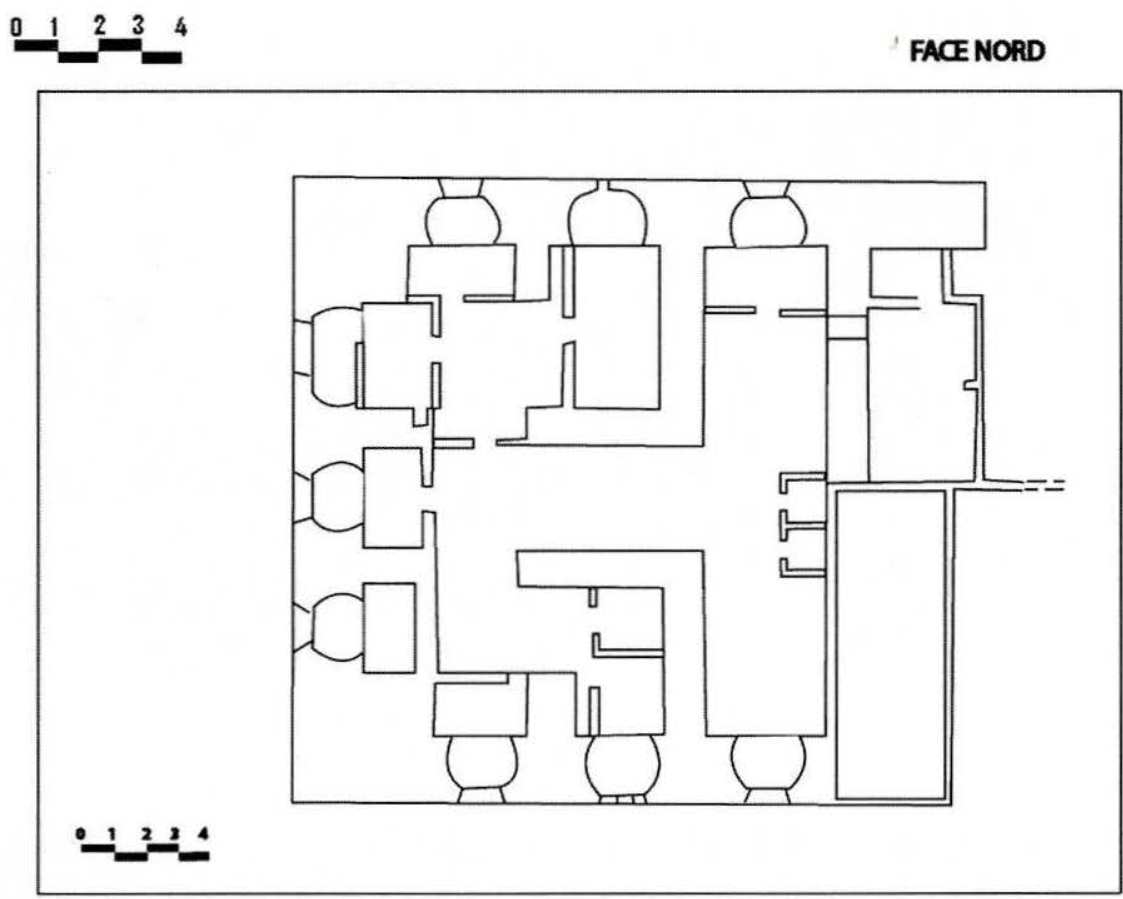

Fig. 18. Burğ Butuil.

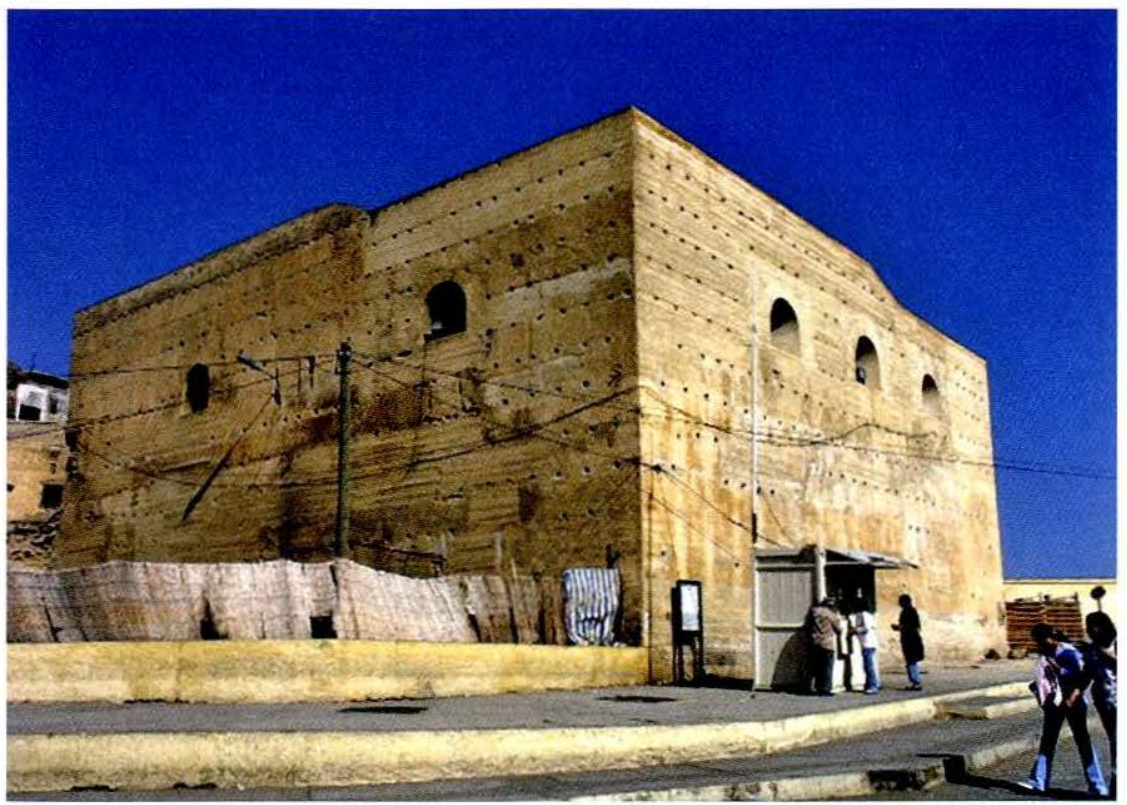

Fig. 19. Burğ Būțuîl, vista de las fachadas exteriores. 


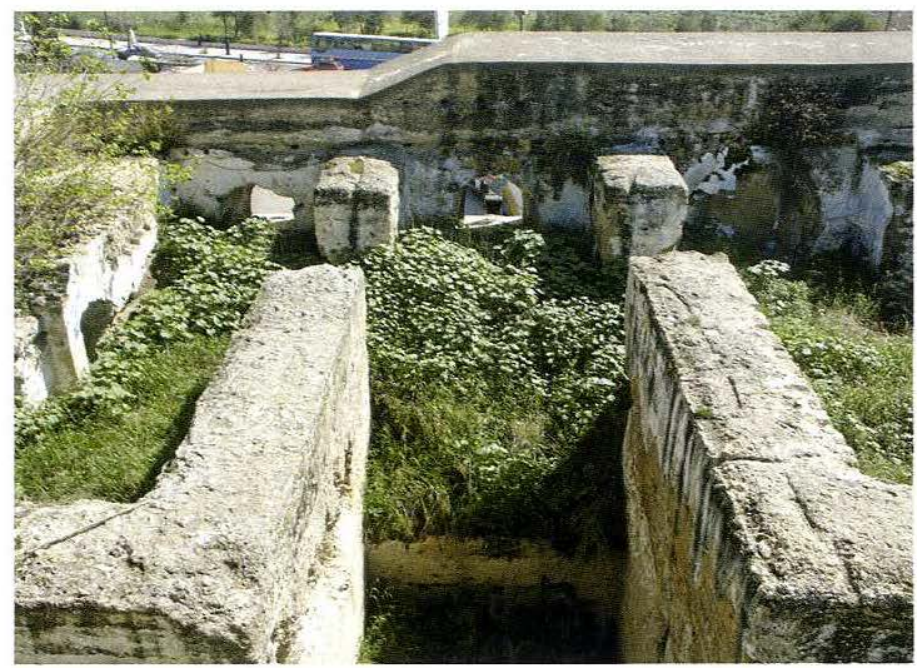

Fig. 20. Burğ Būṭuīl, vista de los espacios interiores

La terraza está metida directamente sobre los techos de la planta sin ningún elemento arquitectónico encima, lo que indica que la utilización de cañones en este Burğ no tenía lugar. La altura de los niveles Norte, Sur, y Este presenta una diferencia de un metro causada por la construcción del edifico en tapial; técnica utilizada en todo el macizo desde la base hasta el la terraza, la mampostería de las aberturas para cañones es a base de ladrillo (Fig. 21).

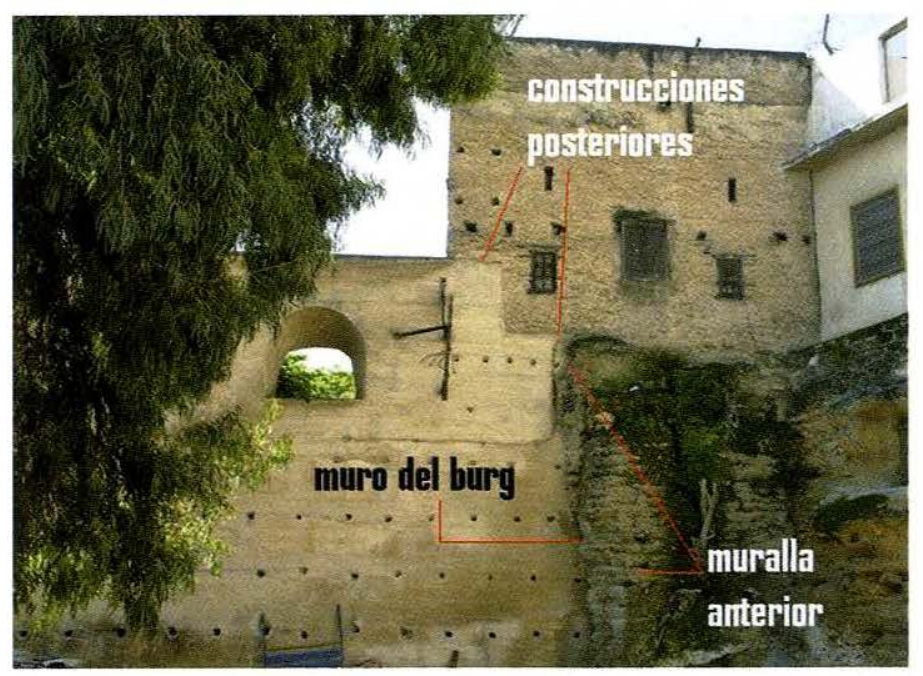

Fig. 21. Burğ Būțuīl, muralla anterior y espacios posteriores 


\section{BURĞ AS̆-ŠAYH AḤMAD}

Este Burğ es el más grande y más representativo por sus proporciones, limitado al Sur por una doble muralla de época anterior, al Norte y al Este por el jardín de $\breve{G n a n ~ S b i ̄ l, ~ a l ~ O e s t e ~ p o r ~ l a s ~ c o n s t r u c c i o n e s ~ n u e v a s ~ q u e ~ s e ~ a d o s a n ~ a ~ l a ~ m u r a l l a ~(F i g . ~ 22) . ~}$

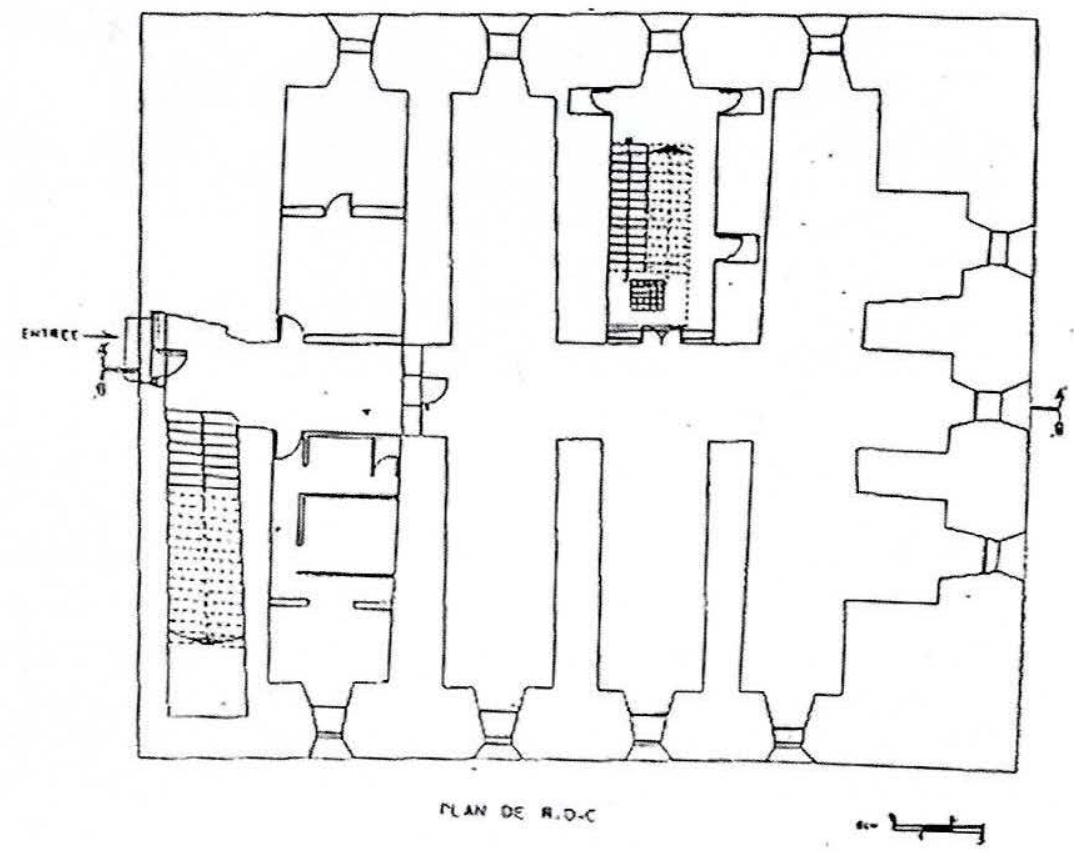

Fig. 22. Burğ aš-Šayh Ahmad, planta.

Se puede acceder al interior del Burğ por el lado oeste a través un paseo reciente entre la doble muralla, dos calles estrechas comunicaban con las puertas del fuerte. La situación del edifico cerca del paseo de una parte del río "oued Fez".

Al lado Norte, una puerta se abre al jardín de Ğnan Sbīl, cuya puerta se interpreta como una antigua puerta de traición ${ }^{13}$.

13. KAFAS, Samir, "Les fortifications et l'architecture militaire du Maroc au temps des Saadiens (XVI e Siècle - XVII e Siècle), Thèse du troisième cycle de l'Institut National des Sciences de l'Archéologie et du Patrimoine (I.N.S.A.P), p. 117. 
Se trata de un enorme macizo de forma casi cuadrada, que tiene las medidas siguientes: $21.30 \mathrm{~m} \times 20.30 \mathrm{~m}$, la plataforma está caracterizada por su larga anchura, y los niveles del suelo interior del monumento presentan una diferencia con el suelo de la calle, que se encuentra en un nivel más bajo (Fig. 23)

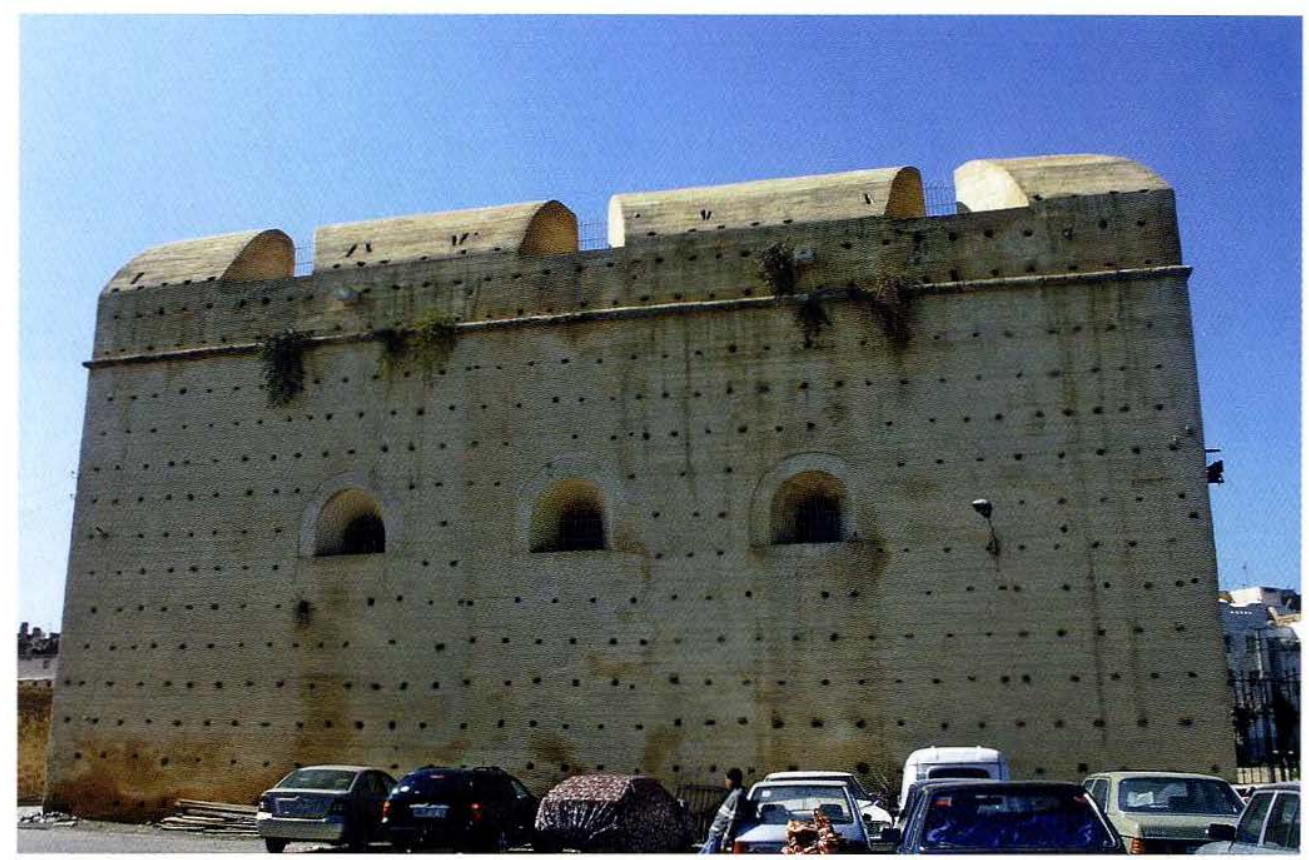

Fig. 23. Burğ aš-Šayh Ahmmad,

Caracterizadas por sus volúmenes enormes, las cuatro esquinas del edificio constituyen con los muros los elementos que soportan el peso de las bóvedas.

En el interior del edificio, un vestíbulo de largas dimensiones $(9.26 \mathrm{~m} . \mathrm{x} 3$ m) está situado en la entrada, cubierto de una bóveda y lleva hasta un patio de dimensiones reducidas $9 \mathrm{~m} \times 3 \mathrm{~m}$. Tres casamatas rectangulares llevan bóvedas y sus entradas llevan arcos, mientras la tercera casamata lleva a unas escaleras que conducen a la parte baja del bastión que va por su parte al jardín de Ğnan Sbīl; actualmente, esta puerta está condenada.

En el eje norte sur, una cámara par fuego de forma rectangular está provista de tres casamatas por el lado este, y otras dos bocas de cañón en sus lados meridional y norte, con un techo en bóveda. 
El acceso a la terraza se hace por una escalera situáda a la derecha de la entrada del fuerte. Caja dividida en dos niveles separados por un murito de forma irregular.

La terraza, de forma rectangular, presenta las medidas siguientes: $29.30 \mathrm{x}$ $21.15 \mathrm{~m}$, en el centro se encuentra un hueco que permite pasar el aire a la planta, con un parapeto alrededor, el lado este lleva tres cañoneras y dos aberturas para el tiro, mientras los lados norte y sur llevan una cañonera de cada lado, y varias aberturas para el tiro.

El lado occidental, cuya mirada se alza frente a Fās al-Ğdīd no dispone de cañoneras para asegurar el tiro, excepto dos huecos en la esquina norte-oeste de la terraza.

La técnica de construcción es la edificación en tapial en varios volúmenes: muros desde la base hasta la terraza, cortinas, parapeto, los muros del fondo y los de la separación. Llenando el espacio sometido entre los muros del fondo y las cortinas, las esquinas forman unos volúmenes macizos soportando las cargas emitidas por la terraza y las bóvedas.

Las bocas para cañones de la planta se construyeron en un espacio hecho entre dos paredes, y arregladas en ladrillo con la forma de un arco (Fig. 24).

La terraza está construida encima de las bóvedas de la planta, mientras el suelo se arregla con arcilla compactada llamada "dess" por los constructores.

En la base, se utilizaba una arcilla mezclada con una cantidad de cal para la obtención de hormigón de gran resistencia, mientras la piedra esta utilizada en las fundaciones. El ladrillo está presente en la construcción de las bóvedas, los arcos y las bocas para cañones.

A través de este artículo, podemos destacar que esas fortificaciones descritas de la ciudad de Fās al-Ğdīd son de época del sultán Ahmed el-Mansur ad-Dahbi. No podemos aceptar la hipótesis de una intervención tardía de los alauitas en el Bastión Norte como pretende Georges Marçais ${ }^{14}$, debido a la armonía de la arquitectura del Bastión por una parte, y al texto de al-Fashtali por otra parte que señalaba: “...el Burğ

14 Marçais, Georges., L'architecture Musulmane d'Occident, Tunisie, Algérie, Maroc, Espagne et Sicile, Paris, 1954. p. 406. 


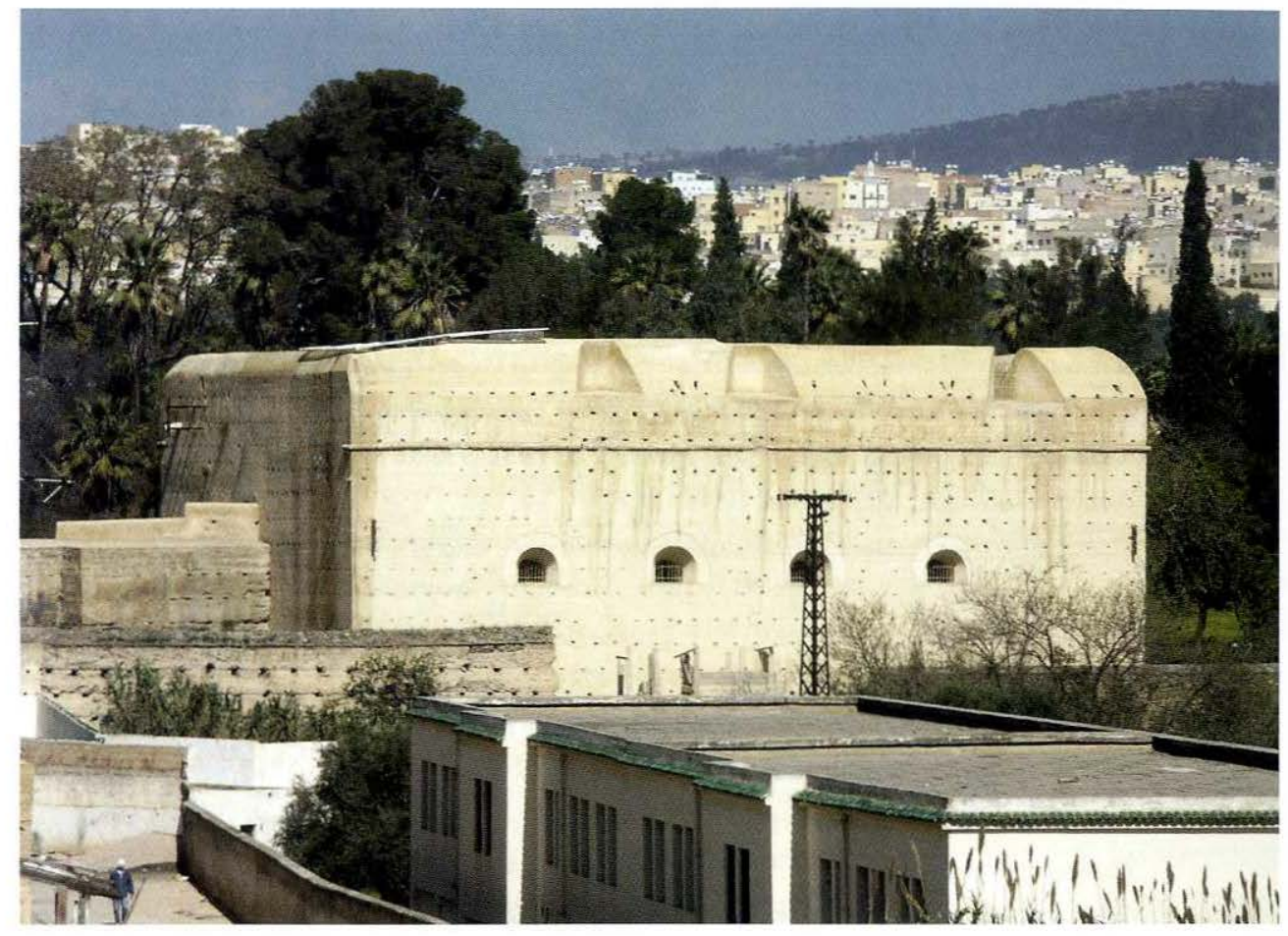

Fig. 24. Burğ aš - Šayh Aḥmad, planta.

se impone por sus grandes masas y sus ángulos de forma triangular..."; pero esas fortificaciones que se utilizaron en la época alauita, expresan la voluntad de una inscripción del Estado Saadino en el prestigio de una tendencia poliorcética, al igual que los otros Estados del Mediterráneo. 


\section{BIBLIOGRAFÍA}

\section{FUENTES:}

Al-Fashtali, "Manahil as-Safa fi ahbar maualina ashurafa”.

Al-Ifrani, "Nuzhat al-Hadi Bi-Ajbar Muluk al-Qarn al-Hadi” (Noticias de los reyes del siglo once), Casablanca, 1998. (árabe)

An-Nasiri Es-Selaui, Ahmed Ben Jaled., Kitab Alistic-sá Liajbari Doual Alac-sá (Historia completa de los Estados de Marruecos), segundo tomo, Edición Dar alkutub al'ilmia, Beirut, 2007. (árabe)

Mağhul (Anónimo), “Tarij addaula assaadia attagmadartia” (Historia del Estado Saadino Tagmderti), edición oiun makalat, Marrakech, 1994. (árabe)

Mármol de Carvajal, África, Traducción al árabe por Mohamed Hağği y otros, Tomo II, Rabat, 19881989. (árabe)

\section{REFERENCIAS:}

Bravo Nieto, Antonio (1993). «Fortificaciones hispanas en la frontera norteafricana». In: Actas Congreso Internacional: Fortificación y Frontera Marítima, Ajuntament d'Eivissa, 2005. (CD-ROM).

Al-Idrissi, Mohamed Mohcine, L'espace urbain et l'Architecture de Fas al-Bali à l'époque 'Alawite (jusqu'au Protectorat), Thèse du Diplôme du troisième cycle, Institut National des Sciences de l'Archéologie et du patrimoine, Rabat, 2002.

Kafas, Samir, Les fortifications sâadiennes au Maroc, Thèse du Diplôme du troisième cycle, Institut National des Sciences de l'Archéologie et du patrimoine, Rabat. 2004.

Le Tourneau, Roger., Fès avant le Protectorat, traducción al árabe por Mohamed Hağği y Mohamed Lakhdar, tomo primero, edición dar al-ğharb al-islami, Beirut, 1992.

Marçais, Georges., L'architecture Musulmane d'Occident, Tunisie, Algérie, Maroc, Espagne et Sicile, Paris, 1954.

Mokaddem, Hafid (2007), "Réhabilitation du Bordj Nord de Fès", in: Le patrimoine marocain, revue de l'Association des Lauréats de l'Institut des Sciences d'Archéologie et du Patrimoine, $\mathrm{n}^{\circ}$ 1, 2008. 